\title{
Oncology
}

\section{A Specific Type of Tibetan Medicine Meditation for Women with Breast Cancer: A Pilot Survey}

\author{
Gioacchino Pagliaro ${ }^{a}$ Francesco Bernardini ${ }^{b}$ \\ a Unit of Hospital Psychology, Oncology Department, Bellaria Hospital, Bologna, Italy; ${ }^{\mathrm{b}}$ Department of Psychology, \\ University of Bologna, Bologna, Italy
}

\section{Keywords}

Meditation - Tibetan medicine · Breast cancer ·

Mindfulness · Quality of life

\begin{abstract}
Background: Breast cancer is one of the most common tumors in the world and is associated with high psychological distress such as depression, anxiety, and stress. Meditation is efficacious to reduce psychological distress, but there are no studies which have evaluated a specific type of Tibetan medicine meditation in patients with breast cancer. The present research aimed to understand the effect a specific type of Tibetan medicine meditation on psychological distress in a sample of women with breast cancer. Methods: Sixty-two women with breast cancer were enrolled. We instructed the patients in Tibetan medicine meditation (five sessions). We administered the Profile of Mood States at baseline and follow-up, after five sessions of Tibetan medicine meditation. Results: The mean age of the sample was 51.08 years (SD = 11.74). There was a significant decrease in scores between baseline and follow-up in anxiety-tension $(F=23.188, p<$ $0.001)$, depression-dejection $(F=19.082, p<0.001)$, angerhostility $(F=18.732, p<0.001)$, fatigue $(F=17.883, p<0.001)$,
\end{abstract}

and confusion ( $F=15.479, p<0.001)$, and there was an increase in the vigor subscale, but it was not statistically significant $(F=1.422, p=0.234)$. Conclusions: This study shows for the first time that a specific form of Tibetan medicine meditation is efficacious in decreasing the psychological distress in women with breast cancer and can be an important complementary therapy to oncological care.

ㄷ) 2019 S. Karger AG, Basel

\section{Introduction}

Breast cancer is the most common tumor in the world [1]. In the United States, the lifetime risk of a breast cancer diagnosis in women is $12.4 \%$ [2]. This illness affects all dimensions of the human being [3], causing a physical, psychological, and social compromise [4] and a worsening of quality of life [5]. The prevalent psychological symptoms are depression, anxiety, and stress $[6,7]$. It is estimated that major depressive disorders have a prevalence that goes from 5 to $>20 \%$ after the diagnosis of breast cancer [8] and that $38.2 \%$ of patients report a depressive symptomatology [9]. Sixteen percent of women with breast cancer suffer from anxiety disorders and 19\%

\section{KARGER}

(c) 2019 S. Karger AG, Basel

E-Mail karger@karger.com

www.karger.com/ocl
Gioacchino Pagliaro

Ospedale Bellaria

Via Altura 3

IT-40139 Bologna (Italy)

E-Mail gioacchino.pagliaro@ ausl.bologna.it 
report anxiety symptoms [10]. Psychological distress is associated with minor compliance levels with medical treatment [9]. Cancer is also associated with physical pain, sleep disorders, nausea, fatigue, anger, hopelessness, fear for the future, and denial $[3,4,11-13]$.

Some limits of the medical approach in cancer patient management are recognized [14], and there is a growing interest in complementary and alternative therapies which may help the management of multidimensional aspects of the disease [3]. It is possible to use some specific subcategories when complementary and alternatives therapies are considered, such as mind-body practices and dietary supplements [15].

Mind-body practices include meditation, yoga, qi gong, acupuncture, and massage [15]. Meditation is recommended as grade A (it means that a high certainty of benefit is substantial) for reducing depression and anxiety as well as for improving quality of life [16]. Besides, the meditation group provides social support for patients who are facing this illness [17]. There is also evidence that relaxation improves depressive symptoms [16]. In general, the term meditation means a training in mental presence which, through the quieting of the mind and a deeper level of awareness, acts on the physical, energetic, mental, and spiritual level, favoring the energetic balance of the individual and microcosm and at the same time maintaining the balance between the latter and the energy system of the macrocosm [18-20].

There are several scientific studies that have highlighted how meditation produces specific physiological answer patterns that imply several biological systems [21]. Meditation produces effects on the metabolic, endocrine, autonomic, neurological, cardiovascular, and psychological levels [22]. Meditation includes changes in cortisol levels, heart rate, and blood pressure [23], and it can influence gene expression [24]. In addition, better mitochondrial energy [24], improvement of sleep quality [25], and increased cortical thickness [26] have been reported.

There are different types of meditation [27]. The aim of the present study was to evaluate the effect of a specific type of Tibetan medicine meditation on psychological distress in a sample of women with breast cancer who were under chemotherapeutic treatment. This Tibetan medicine meditation is an integrant part of a method called Harmoniously, which is made up of three pillars. Pillar number 1: make the patients aware about the different stages of the course of treatment of the illness through a series of weekly meetings in which several doctors illustrate their activity to them. Pillar number 2: health education interventions. Some medical specialists give dietary advice for cancer prevention and indications on the importance of physical activity. Doctors show the advantages of acupuncture for the treatment of some side effects of the therapies. Pillar number 3: meditation on Tibetan medicine with the aim to balance and harmonize the patient's energy system. This meditation originated from Tibetan medicine; it has been adapted to Western culture thanks to the experience of Dr. Pagliaro who trained with Tibetan doctors. This method has been recognized by the oncology department of Bellaria Hospital in Bologna and is used in various Italian hospitals.

\section{Methods}

\section{Sample}

The sample was recruited at the unit of hospital psychology of Bellaria Hospital in Bologna from 2013 to 2017. The inclusion criterion was a diagnosis of breast cancer. Exclusion criteria were physical difficulties of the patients to follow meditation practices and lack of time due to medical therapies.

\section{Assessment}

We administered the Profile of Mood States (POMS) [28] both at baseline and at follow-up (after five sessions of meditation). The POMS contains 65 self-report items that use the five-point Likert Scale: $0=$ not at all, $1=$ a little, $2=$ moderately, $3=$ quite a bit, and 4 = extremely. Patients can choose from 0 (not at all) to 4 (extremely). Items were subclassified into six factors: anxiety-tension, depression-dejection, anger-hostility, vigor, fatigue, and confusion. High levels of reliability and validity were reported [29].

\section{Meditation Protocol}

Five weekly sessions in which the group of patients progressively learns the phases of Tibetan medicine meditation are offered. Each session opens with a brief discussion, with all participants aimed at verifying whether the meditation was performed correctly and with a daily frequency of twice. Each session lasts $2 \mathrm{~h}$.

First Session. Presentation of the patients and brief description of their expectations. Presentation by the conductor of the meditation and the effects from scientific evidence. Mental presence training. Final discussion.

Second Session. Group discussion on the previous week's session. Mental presence and visualization of a beneficial energy in the shape of a sphere of white light displayed at a distance of about $20 \mathrm{~cm}$ from the their head. End of the session and group discussion.

Third Session. Group discussion on the previous week's session. Mental presence. Visualization of beneficial energy in the shape of a sphere of white light. The patient imagines that the sphere is positioned at a precise point of the chest and then it starts to border the area around the wound leaving a luminous trail (a perimeter of light). The patient is invited to imagine this thread of light as a beneficial energy that acts around the wound. Session closure and group discussion. 
Table 1. Differences in mean POMS scores between baseline and follow-up

\begin{tabular}{lllcc}
\hline POMS & $\begin{array}{l}\text { Baseline } \\
(\text { mean } \pm \text { SD) }\end{array}$ & $\begin{array}{l}\text { Follow-up } \\
(\text { mean } \pm \text { SD) }\end{array}$ & $F$ & $p$ \\
\hline Anxiety-tension & $52.52 \pm 10.97$ & $47.47 \pm 9.68$ & 23.188 & $<0.001^{* *}$ \\
Depression-dejection & $55.37 \pm 12.55$ & $48.77 \pm 10.53$ & 19.082 & $<0.001^{* *}$ \\
Anger-hostility & $55.73 \pm 13.35$ & $48.44 \pm 10.24$ & 18.732 & $<0.001^{* *}$ \\
Vigor & $45.21 \pm 11.54$ & $47.19 \pm 12.55$ & 1.422 & 0.238 \\
Fatigue & $56.47 \pm 12.91$ & $49.37 \pm 11.89$ & 17.883 & $<0.001^{* *}$ \\
Confusion & $55.26 \pm 12.68$ & $49.53 \pm 9.66$ & 15.479 & $<0.001^{* *}$ \\
\hline \multicolumn{2}{c}{ POMS, Profile of Mood States. ${ }^{*} p<0.05,{ }^{* *} p<0.01}$. \\
\hline
\end{tabular}

Fourth Session. Group discussion on the previous week's session. Mental presence. Visualization of the sphere of light that borders the area around the wound. The patient imagines that the sphere of light radiates the light inwards in order to transform the perimeter into a luminous air. Session closure and group discussion.

Fifth Session. Group discussion on the previous week's session. Mental presence. Visualization of the sphere of light that borders the area around the wound. Then the patient imagines that the surface of the luminous surface radiates into the whole organism, transforming it into a luminous body. At this stage it is important that all the patients associate a feeling of joy and happiness with what they are doing in their body. All patients imagine that the light produces an increase in the effectiveness of the treatments they are following (chemotherapy) and reduces side effects. Session closure and final discussion.

\section{Statistical Analysis}

Descriptive analysis of the data was performed using summary statistics for categorial and quantitative (continuous) data. Continuous data were described as means with SD. Repeated-measures ANOVA was performed to test the potential effect of meditation on psychological distress. Data were analyzed using SPSS version 20.0 .

\section{Results}

The study included sixty-two participants ranging in age from 31 to 78 years $($ mean $=51.08, S D=11.74)$ who had been diagnosed with breast cancer and were under chemotherapeutic treatment. Of these, $45.8 \%$ had a high school diploma, 33.3\% had a degree, and $20.8 \%$ had a third-grade diploma. The POMS results are summarized in Table 1. From the first evaluation at baseline, the mean score on the POMS was 52.52 (SD = 10.97) for anxietytension, 55.37 ( $\mathrm{SD}=12.55)$ for depression-dejection, 55.73 ( $\mathrm{SD}=13.35)$ for anger-hostility, $45.21(\mathrm{SD}=11.54)$ for vigor, $56.47(\mathrm{SD}=12.91)$ for fatigue, and $55.26(\mathrm{SD}=$

Tibetan Medicine Meditation for Women with Breast Cancer
12.68) for confusion. At follow-up of five meditation sessions, the mean score on the POMS was $47.47(\mathrm{SD}=9.68)$ for anxiety-tension, 48.77 ( $\mathrm{SD}=10.53$ ) for depressiondejection, $48.44(\mathrm{SD}=10.24)$ for anger-hostility, 47.19 ( $\mathrm{SD}=12.55)$ for vigor, 49.37 ( $\mathrm{SD}=11.89)$ for fatigue, and 49.53 ( $\mathrm{SD}=9.66$ ) for confusion. There was a significant decrease between baseline and follow-up scores in anxiety-tension $(F=23.188, p<0.001)$, depression-dejection $(F=19.082, p<0.001)$, anger-hostility $(F=18.732, p=$ $0.001)$, fatigue $(F=17.883, p<0.001)$, and confusion $(F=$ $15.479, p<0.001)$. There was an increase for the vigor subscale, but it was not significant $(F=1.422, p=0.238)$.

\section{Discussion}

Our research highlighted how this specific form of Tibetan medicine meditation is very efficacious for the reduction of psychological distress in women with breast cancer. Levels of anxiety, depression, anger, fatigue, and confusion decreased significantly at the end of the five sessions of this Tibetan medicine meditation. Some research has reported significant effects of meditation on depression, anxiety, and quality of life $[16,30]$ in patients with cancer, but to the best of our knowledge no study has been carried out on this specific form of meditation in a sample of women with breast cancer. Our research highlighted not only an improvement of psychological aspects, but also an enhancement of the somatic dimension like fatigue that significantly decreased by means of this Tibetan medicine meditation. This is an important fact since fatigue is often reported by women undergoing chemotherapy or radiation treatment $[31,32]$. There is no solid evidence of the efficacy of psychological interventions in the reduction of fatigue in the treatment of cancer 
patients [33]. Other mind-body practices like yoga have shown some beneficial effects in women with breast cancer $[34,35]$.

The strength of the present research is that it is the first study which investigated the effects of Tibetan medicine meditation on psychological distress in a sample of women with breast cancer. We examined psychological distress, but it would be interesting to know how this Tibetan medicine meditation may affect the psychological well-being and quality of life in these patients.

This research has some limitations that should be discussed. First, it involves a small sample size that may not be representative and may limit the power to detect significant differences. Second, we did not include a control group of patients who did not practice meditation. Third, we did not control whether the patients had practiced meditation at home as they were requested to do.
In conclusion, our findings show that this Tibetan medicine meditation significantly reduced the psychological distress in women affected by breast cancer and that, if this effectiveness is proved by other studies, clinicians will have to lay more emphasis on Tibetan medicine meditation.

\section{Statement of Ethics}

All participants gave their informed consent for the use of personal data in order to join the study. The study protocol was approved by the institute's committee on human research.

\section{Disclosure Statement}

The authors have no conflicts of interest to declare.

\section{References}

1 Akram M, Iqbal M, Daniyal M, Khan AU. Awareness and current knowledge of breast cancer. Biol Res. 2017 Oct;50(1):33.

2 Howlader N, Noone AM, Krapcho M, Miller D, Bishop K, Kosary CL, et al. SEER Cancer Statistics Review, 1975-2014, based on November 2016 SEER data submission, posted to the SEER web site, April 2017 (seer.cancer. gov/csr/1975_2014/). Bethesda, MD: National Cancer Institute; 2017.

3 Liu S, Qiu G, Louie W. Use of Mindfulness Sitting Meditation in Chinese American Women in Treatment of Cancer. Integr Cancer Ther. 2017 Mar; 16(1):110-7.

4 Jang SH, Kang SY, Lee HJ, Lee SY. Beneficial Effect of Mindfulness-Based Art Therapy in Patients with Breast Cancer - A Randomized Controlled Trial. Explore (NY). 2016 SepOct;12(5):333-40.

5 Salibasic M, Delibegovic S. The Quality of Life and Degree of Depression of Patients Suffering from Breast Cancer. Med Arh. 2018 Jun; 72(3):202-5.

6 Puigpinós-Riera R, Graells-Sans A, Serral G, Continente X, Bargalló X, Domènech M, et al. Anxiety and depression in women with breast cancer: social and clinical determinants and influence of the social network and social support (DAMA cohort). Cancer Epidemiol. 2018 Aug;55:123-9.

7 Witek Janusek L, Tell D, Mathews HL. Mindfulness based stress reduction provides psychological benefit and restores immune function of women newly diagnosed with breast cancer: a randomized trial with active control. Brain Behav Immun. 2019 Apr:S0889-1591 (18)30547-6.
8 Thompson LM, Bobonis Babilonia M. Distinguishing Depressive Symptoms From Similar Cancer-Related Somatic Symptoms: Implications for Assessment and Management of Major Depression after Breast Cancer. South Med J. 2017 Oct;110(10):667-72.

9 Tsaras K, Papathanasiou IV, Mitsi D, Veneti A, Kelesi M, Zyga S, et al. Assessment of Depression and Anxiety in Breast Cancer $\mathrm{Pa}$ tients: Prevalence and Associated Factors. Asian Pac J Cancer Prev. 2018 Jun;19(6): 1661-9.

10 Lueboonthavatchai P. Prevalence and psychosocial factors of anxiety and depression in breast cancer patients. J Med Assoc Thai. 2007 Oct;90(10):2164-74.

11 Chen PY, Chang HC. The coping process of patients with cancer. Eur J Oncol Nurs. 2012 Feb;16(1):10-6.

12 Costa AR, Fontes F, Pereira S, Gonçalves M, Azevedo A, Lunet N. Impact of breast cancer treatments on sleep disturbances - a systematic review. Breast. 2014 Dec;23(6):697-709.

13 Zimmermann FF, Burrell B, Jordan J. The acceptability and potential benefits of mindfulness-based interventions in improving psychological well-being for adults with advanced cancer: A systematic review. Complement Ther Clin Pract. 2018 Feb;30:6878.

14 Gordon DB, Dahl JL, Miaskowski C, McCarberg B, Todd KH, Paice JA, et al. American pain society recommendations for improving the quality of acute and cancer pain management: American Pain Society Quality of Care Task Force. Arch Intern Med. 2005 Jul;165(14):1574-80.
15 Greenlee H, Neugut AI, Falci L, Hillyer GC, Buono D, Mandelblatt JS, et al. Association Between Complementary and Alternative Medicine Use and Breast Cancer Chemotherapy Initiation: The Breast Cancer Quality of Care (BQUAL) Study. JAMA Oncol. 2016 Sep;2(9):1170-6.

16 Lyman GH, Greenlee H, Bohlke K, Bao T, DeMichele AM, Deng GE, et al. Integrative Therapies During and After Breast Cancer Treatment: ASCO Endorsement of the SIO Clinical Practice Guideline. J Clin Oncol. 2018 Sep;36(25):2647-55.

17 Koula MJ, Knight JM. Increasing provider awareness of and recommendations for yoga and meditation classes for cancer patients. Support Care Cancer. 2018 Oct;26(10):363540.

18 Pagliaro G. Mente, meditazione e benessere. Medicina tibetana e psicologia clinica. Milano: Tecniche Nuove; 2004

19 Pagliaro G, Martino E. La mente non localizzata. La visione olistica e il modello mentecorpo in psicologia e medicina. Padova: UPSEL Domeneghini; 2010.

20 Pagliaro G, Salvini A. Mente e psicoterapia. Modello Interattivo-Cognitivo e Modello Olistico. Novara: Utet Università; 2007.

21 Sinha SS, Jain AK, Tyagi S, Gupta SK, Mahajan AS. Effect of 6 Months of Meditation on Blood Sugar, Glycosylated Hemoglobin, and Insulin Levels in Patients of Coronary Artery Disease. Int J Yoga. 2018 May-Aug;11(2): 122-8.

22 Wallace RK, Benson H, Wilson AF. A wakeful hypometabolic physiologic state. Am J Physiol. 1971 Sep;221(3):795-9. 
23 Dangayach NS, O'Phelan KH. Understanding the Functional Neuroanatomical Basis of Meditation for Improving Patient Wellness and Outcomes. World Neurosurg. 2018 Apr; 112:294-6.

24 Bhasin MK, Dusek JA, Chang BH, Joseph MG, Denninger JW, Fricchione GL, et al. Relaxation response induces temporal transcriptome changes in energy metabolism, insulin secretion and inflammatory pathways. PLoS One. 2013 May;8(5):e62817.

25 Wang F, Lee OEK, Feng F, Vitiello MV, Wang $\mathrm{W}$, Benson $\mathrm{H}$, et al. The effect of meditative movement on sleep quality: a systematic review. Sleep Med Rev. 2016 Dec;30:43-52.

26 Lazar SW, Kerr CE, Wasserman RH, Gray JR, Greve DN, Treadway MT, et al. Meditation experience is associated with increased cortical thickness. Neuroreport. 2005 Nov;16(17): 1893-7.
27 Levine GN, Lange RA, Bairey-Merz CN, Davidson RJ, Jamerson K, Mehta PK, et al.; American Heart Association Council on Clinical Cardiology; Council on Cardiovascular and Stroke Nursing; and Council on Hypertension. Meditation and Cardiovascular Risk Reduction: A Scientific Statement From the American Heart Association. J Am Heart Assoc. 2017 Sep;6(10):e002218.

28 McNair DM, Droppleman LF. Manual for the Profile of Mood States. San Diego (CA): Educational and Industrial Testing Services; 1971.

29 McNair DM, Lorr M, Droppleman LF; Educational and Industrial Testing Service. Profile of Mood States. San Diego, CA: Educational and Industrial Testing Service; 1992.

30 Goyal M, Singh S, Sibinga EM, Gould NF, Rowland-Seymour A, Sharma R, et al. Meditation programs for psychological stress and well-being: a systematic review and metaanalysis. JAMA Intern Med. 2014 Mar;174(3): 357-68.
31 Prue G, Rankin J, Allen J, Gracey J, Cramp F. Cancer-related fatigue: A critical appraisal. Eur J Cancer. 2006 May;42(7):846-63.

32 Bardwell WA, Ancoli-Israel S. Breast Cancer and Fatigue. Sleep Med Clin. 2008 Mar;3(1): 61-71.

33 Goedendorp MM, Gielissen MF, Verhagen CA, Bleijenberg G. Psychosocial interventions for reducing fatigue during cancer treatment in adults. Cochrane Database Syst Rev. 2009 Jan;1:CD006953.

34 Danhauer SC, Tooze JA, Farmer DF, Campbell CR, McQuellon RP, Barrett R, et al. Restorative yoga for women with ovarian or breast cancer: findings from a pilot study. J Soc Integr Oncol. 2008;6(2):47-58.

35 Cramer H, Lange S, Klose P, Paul A, Dobos G. Can yoga improve fatigue in breast cancer patients? A systematic review. Acta Oncol. 2012 Apr;51(4):559-60. 